\title{
Reproductive biology of Withania ashwagandha sp. novo (Solanaceae)
}

\author{
Bilal Ahmad Mir ${ }^{\mathrm{a}, \mathrm{b},},{ }^{*}$ Sushma Koul ${ }^{\mathrm{b}}$, Amarjit Singh Soodan ${ }^{\mathrm{c}}$ \\ ${ }^{a}$ Centre for Microbial Ecology and Genomics, Department of Genetics, University of Pretoria 0002, South Africa \\ ${ }^{\mathrm{b}}$ Biodiversity and Applied Botany Division, Indian Institute of Integrative Medicine (CSIR), Jammu 180001, India \\ ${ }^{c}$ Department of Botanical and Environmental Sciences, Guru Nanak Dev University, Amritsar, India
}

\begin{abstract}
Withania ashwagandha Kaul (Solanaceae) is an annual plant species of immense medicinal importance. It is a repository of a large number of pharmacologically active secondary metabolites known as withanolides. Evidence for the delimitation of the species from $W$. somnifera has been provided by our group using multidisciplinary approaches. Knowledge of reproductive biology of medicinal plants is crucial for improvement, effective conservation and management plans to evolve genetically superior varieties. The present paper reports our findings on the floral biology, pollination behavior and breeding system of $W$. ashwagandha in natural populations grown at our experimental field under near natural conditions. Flowering (peak) takes place during April-July and anthesis occurs between 08:00 and 11:00 h. The period of stigma receptivity coincides with anther dehiscence. Fruit set on pollination treatments ranged from $90.8 \%$ (passive autogamy), $72 \%$ (assisted autogamy), 30.30\% (xenogamy), and 56.50\% (geitonogamy) through $50.40 \%$ (open pollination). Xenogamy brings about very low fruit set, seed-set and seed germination percentages. It is inferred that $W$. ashwagandha is predominantly an autogamous and self-compatible species. Self-compatibility is mainly accomplished due to close proximity of stigma and anthers. This work is the first report on the reproductive biology of $W$. ashwagandha and will be useful for conservation and development of improved varieties of this multipurpose herb.
\end{abstract}

\section{Highlights}

Reproductive biology of $W$. ashwagandha Kaul was reported first time.

We report the species to be highly self compatible due to close proximity of stigma and anthers.

- The period of stigma receptivity coincides with anther dehiscence.

Fruit set on pollination treatments ranged between $90.8 \%$ (passive autogamy) and $30.30 \%$ (xenogamy).

Xenogamy brings about very low fruit set, seed-set and seed germination percentages.

Keywords: Withania ashwagandha; Floral biology; Pollination biology; Withanolides; Autogamy 


\section{Introduction}

Understanding pollination and breeding systems that regulate the genetic structure of populations is important for determining the reproductive constraints in conservation and management (Kaye, 1999 and Koul and Bhatnagar, 2007). Besides quality improvement of medicinal plants, cultivation of medicinal plants is a challenging task because less is known about their reproductive and seed biology (Anderson and Hill, 2002, Anderson et al., 2006, Neal and Anderson, 2005 and Kaul et al., 2005). Equally important is the pollination behavior of the species which is an integral part of reproductive biology.

The genus Withania is represented by 26 species worldwide. India is a host to only two species, $W$. somnifera and $W$. coagulans. A variety of breeding systems ranging from obligate selfing to obligate out-crossing operate in different species of medicinal plants including Withania ( Lewis and John, 1963, Lalonde and Roitberg, 1994, Kaul et al., 2005, Lattoo et al., 2007 and Singh, 2009). Each one of these systems is accompanied by a syndrome of floral and other characters which favor either autogamy, geitnogamy, xenogamy or a blend of these. W. ashwagandha, has a similar floral architecture as well as mating system to $W$. somnifera. Reproductive biology and breeding systems of $W$. somnifera and $W$. aristata has been extensively studied ( Kaul et al., 2005, Lattoo et al., 2007, Anderson et al., 2006, Singh, 2009 and Mir et al., 2012).

Our research support the delineation of $W$. ashwagandha from $W$. somnifera based on morphology, chemical profiling, crossability features, AFLP fingerprinting and ITS analysis ( Mir et al., 2010 and Kumar et al., 2011). Earlier, Kaul (1957) and Atal and Schwarting (1962) suggested that $W$. somnifera is an amalgamation of two or more taxa. Kaul (1957) proposed a separate species status, $W$. ashwagandha to the cultivated forms in the $W$. somnifera germplasm. Subsequently Sastry et al. (1960) and Dhalla et al. (1961) conducted anatomical, pharmacognostic and chemical studies on $W$. ashwagandha and confirmed its distinct nature from its ally $W$. somnifera. Negi et al. (2006) also confirmed the distinctness of cultivated types on the basis of AFLP and SAMPL studies.

The species is found only in some parts of Madhya Pradesh, Rajasthan and Andhra Pradesh where it exists in small cultivated patches. $W$. ashwagandha shows very low genetic diversity ( Mir et al., 2010 and Mir et al., 2011) which is further shrinking at an alarming rate because of ruinous harvesting practices for the growing demand of the pharmaceutical industry. It forms an essential constituent of over 100 traditional medicinal formulations (Kaileh et al., 2007).

In recent years, there has been a great upsurge in the pharmacological studies of this plant as it has been shown to possess a wide array of therapeutic properties including antitumor, immunoregulatory and anti-inflammatory (Davis and Kuttan, 2002 and Kuttan, 1996). Most of these pharmacological activities are attributed to a novel group of naturally occurring triterpenoid C-28 steroidal lactones called withanolides. One of the well known withanolides, Withaferin A emerged as an important therapeutic molecule of $W$. ashwagandha due its anticancer properties ( Koduru et al., 2010, Lee et al., 2010, Mayola et al., 2011 and Yang et al., 2011). 
Keeping in view the tremendous medicinal importance and a highly restricted distribution of this species, present investigations were envisaged to study the pollination behavior and reproductive biology of the species for progressiveness of conservation, management and genetic improvement.

\section{Materials and methods}

The present study was conducted at the experimental field station of Indian Institute of Integrative Medicine (IIIM) Jammu (32 $44^{\prime} \mathrm{N}$ and $74^{\circ} 55^{\prime} \mathrm{E}$ and $400 \mathrm{~m}$ above the sea level with a temperature range summer $\left(30-44^{\circ} \mathrm{C}\right)$, winter $\left(5-20^{\circ} \mathrm{C}\right)$ and total annual rainfall of $\left.506 \mathrm{~mm}\right)$. Field studies were carried out during 2008-2011. The institute has a very rich germplasm collection of 'ashwagandha'. Inflorescences at the pre-anthesis stage were kept under observation. Emasculation of buds at pre-anthesis stage was done without damaging pistil. The emasculated buds were bagged with perforated wax coated paper bags which were secured at their open ends with thread to prevent contamination. Open flowers close to the emasculated buds were removed. However some flowers were bagged without emasculation to serve as pollen donors for geitonogamy and xenogamy experiments. Depending on pollination treatments flowers could be classified into six categories: (i) Apomixix - anthers removed and flowers bagged to prevent pollination, (ii) Passive Autogamy - intact flowers bagged to ensure selfpollination, (iii) Assisted Autogamy - intact flower buds bagged and pollen grains manually transferred from their anthers to stigma on the next day when it becomes receptive, (iv) Geitonogamy - pollen grains of other flowers of the same plants dusted on the stigma, (v) Xenogamy - pollen grains of other plants of the same population dusted on the stigma and (vi) Open pollination - plants tagged but not bagged. Each of these treatments was based on varied number of crosses and repeated thrice. For manual pollination, pollen grains of dehisced anthers of donor flowers were collected and transferred to receptive stigma of the receptor flowers which were again covered with perforated wax coated bags for the next three days. Receptivity of stigma was tested by $\mathrm{H}_{2} \mathrm{O}_{2}$ method (Dafni, 1992).

Manual pollinations were conducted between 09:00 h and 11:00 h during peak flowering period for four consecutive years, 2008-2011. Twenty plants with triplicate (60 plants each year) were selected randomly at maturity for morphological details (size and color of flowers, petal, stamens, pollen grains, ovary, style, stigma, ovules and number of flowers/flowering shoot, etc.). Floral architecture and phenological data were correlated with breeding system. These included flowering time, flowering duration, anthesis, stigmatic receptivity, anther dehiscence, relative length and position of stigma and anthers during floral ontogeny, fertilization, seed set and fruit maturation. To measure size of pollen grains, ovules, etc. a calibrated ocular micrometer was used. To estimate total pollen per flower, mature anthers were collected $1-2 \mathrm{~h}$ prior to anther dehiscence, put in Ependorf tubes containing $1 \mathrm{ml}$ of a mixture of lactic acid:glycerin (3:1) and kept in the refrigerator $\left(4^{\circ} \mathrm{C}\right)$ till use. A sample of known volume was placed in a hemocytometer where pollen grains were counted; this value was used to estimate the total number of grains per flower. Percentage pollen viability was estimated by $1 \%$ TTC $(2,3,5-$ triphenyl tetrazolium chloride) test (Stanley and Linskens, 1974). Deeply stained pollen grains were treated as viable whereas shrunken and poorly stained as nonviable. Percentage pollen germination was tested from the time of anther dehiscence to $24 \mathrm{~h}$. Pollen grains showing emergence of pollen tubes were recorded as germinated. Scanning Electron Microscopy was 
undertaken to study the detailed structure of pollen surface. For this pollen grains were acetolyzed and mounted on a glass plate according to the method of Caccavari and Dome (2000). Thereafter, plates were prepared for electro-micrographs under Scanning Electron Microscope (JEM-JEOL-100 CX II EM with ASID) at $40 \mathrm{kV}$. Ovule number was obtained from dissections of ovaries under a stereoscopic microscope. Pollen-ovule (p/o) ratio was determined by dividing the number of pollen grains by the number of ovules per flower as described by Cruden (1977) and the mean value of three replications was taken as the correct ratio. Flower visitors were recorded during peak flowering time. Fruit set became visible 3-4 days after fertilization. However percentage fruit set was computed after 40 days. Seeds obtained from the various pollination treatments were germinated in seed germinator at $25^{\circ} \mathrm{C}$ and $24 \mathrm{~h}$ dark period suitable for this species (Mir et al., 2012). However, the apomixis treatment did not result any fruit or seed set. Difference in percentage fruit set and seed germination were analyzed with paired ' $t$ ' test using passive autogamy as control (Mahajan, 1989).

\section{Results}

W. ashwagandha is an annual, evergreen, tomentose medicinal herb that grows unto $40-50 \mathrm{~cm}$. It has ovate, sub acute, stellately pubescent leaves with undulate margin and inconspicuous veins. Six to seven shoots arise from the crown. In the present sample flowering started in the first week of March and lasted till September with a peak period between April and July. Usually 5-8 flowers were present in axillary clusters out of which only one or two flowers were found to be open. Flowers were small $(0.5-0.7 \mathrm{~cm})$, sub-sessile, complete, pentamerous, actinomorphic, hermaphrodite and hypogynous. Sepals $5(0.4-0.6 \mathrm{~cm})$, persistent, gamosepalous, dull green, boat shaped with valvate aestivation enlarging with the development of fruit and finally covering it. Petals $5(0.4-0.5 \mathrm{~cm})$, lurid green colored, gamopetalous, campanulate and arranged in valvate aestivation. Mean floral life span was 8 days $(n=50$ flowers).

Each flower bore five epipetalous and polyandrous stamens and an exerted pistil (Fig. 1). Anthers were oblong, dithecous, basifixed and introse and dehisced longitudinally. On the inner side, they were in touch with stigma that ensured sufficient pollen deposition. Pollen grains were yellow, smooth-walled, sticky and measured $28 \pm 0.07 \mu \mathrm{m}$ (Table 1). There were $4650 \pm 201.5$ pollen/anther and 23,250 \pm 275 pollen/flower. Pollen viability was $82.4 \pm 1.13 \%$ (Table 1 ). The pollen was trizonocolporate and the exine pattern was scabrate-granulate (Fig. 1). The average number of ovules/flower was $38 \pm 1.20$ and the p/o ratio worked to 611:1. Pistil had a wet, capitate, greenish and papillose stigma. The relative length and close proximity of anthers to the stigma coupled with synchrony between stigma receptivity and anther dehiscence indicates the species to be self-pollinated and autogamous. The ovary is bilocular with a large numbers of ovules arranged in axile placentation. 

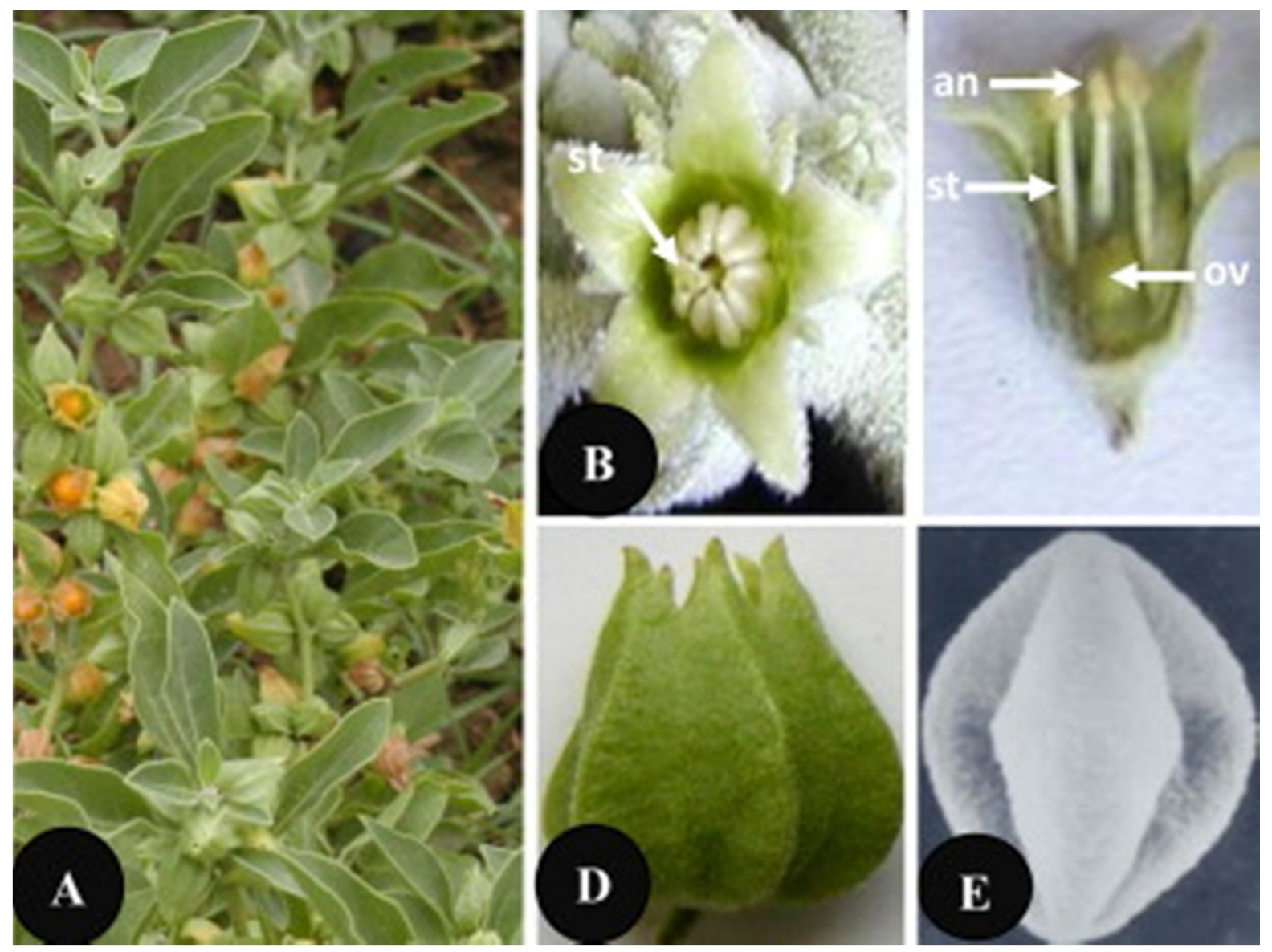

Fig. 1. Withania ashwagandha showing the presence of flowers and young fruits. (A) Fruiting twig with orange berries, (B) Single flower showing arrangement of pistil and stamens and greenish receptive stigma (stg), (C) LS of flower 2 days after anthesis shows dehisced anthers (an), elongated stamens (st) and ovary (ov), (D) Elongated fruiting calyx (Initially fruit is covered with green colored calyx which change into brown on maturation, and (E) Scanning electron micrograph of pollen.

A close perusal of floral phenology revealed that the expansion of petal lobes marked the beginning of anthesis which occurred between 09:00 h and 11:00 h. Apis dorsata, Apis florae, and butterflies were some common visitors despite the scentless nature of the flowers. Insect visits commenced early in the morning with a peak activity from 8:00 to 12:00 h. During the preanthesis phase, the carpel was longer than stamens but by the time anthesis began, stamens had increased in length and exceeded the length of the carpel. The filaments were inserted into stapets or stirrups which were fused with the corolla tube. Stapet (filament base) was adpressed to the ovary and a grove between each stapet allowed nectar to flow upwards from the nectary located at the base of the ovary. After anthesis, the petals were retained for about three days after which they turned brown and withered. Fruiting commences simultaneously with flowering and berries took 30-40 days to ripen. However, maximum fruiting occurred during April-July. The fruiting calyx is elongated and prominently ribbed. The berries were invariably yellow and the seeds were dry in texture (33-36 seeds/berry). Details of reproductive features of the species are presented in Table 1. 
Table 1. Reproductive characters of W. ashwagandha.

\begin{tabular}{|c|c|c|}
\hline S. No. & Parameter & Observations \\
\hline 1. & Flowering season (peak) & April-July \\
\hline 2. & Flower type & Chasmogamous, pentamerous \\
\hline 3. & Flower color & Lurid yellow \\
\hline 4. & Flower odor & Negligible \\
\hline 5. & No. of flowers/node & $3-6$ \\
\hline 6. & Anthesis & $8: 00-11: 00 \mathrm{~h}$ \\
\hline 7. & Anther dehiscence time & $8: 00-11: 00 \mathrm{~h}$ (two days after anthesis) \\
\hline 8. & Anther dehiscence pattern & Longitudinal (inside) \\
\hline 9. & Peak stigma receptivity & synchronous with anther dehiscence \\
\hline 10. & Stigma type & Pappilose wet type \\
\hline 11. & No. of anther/flower & Five \\
\hline 12. & No. of pollen grains/anther & $4650 \pm 201.5(20)$ \\
\hline 13. & No. of pollen grains/flower & 23,250 \\
\hline 14. & Pollen viability (TTC test) & $82.4 \pm 1.13(2320)$ \\
\hline 15. & Pollen shape & Spherical-slightly triangular \\
\hline 16. & Pollen size $(\mu \mathrm{m})$ & $28.0 \pm 0.07$ \\
\hline 17. & No. of ovules/flower & $38 \pm 1.20(25)$ \\
\hline 18. & $\mathrm{p} / \mathrm{o}$ ratio & $611: 1$ \\
\hline 19. & Berry & Orange \\
\hline 20. & Fruiting calyx & Elongated \\
\hline 21. & Seed & Non-oily \\
\hline 22. & No. of seeds/berry & $34 \pm 3$ \\
\hline 23. & Flower length before anthesis $(\mu \mathrm{m})$ & $5.03 \pm 0.022$ \\
\hline 24. & Flower breadth before anthesis $(\mu \mathrm{m})$ & $4.50 \pm 0.022$ \\
\hline 25. & Flower length after anthesis $(\mu \mathrm{m})$ & $5.33 \pm 0.018$ \\
\hline 26. & Flower breadth after anthesis $(\mu \mathrm{m})$ & $5.23 \pm 0.020$ \\
\hline
\end{tabular}

Data averaged from 20 replications. Values in parenthesis are number of observations.

Manual pollination of flowers with self pollen resulted in $90.8 \%$ fruit set which was only $65 \%$ in active autogamy and $56.5 \%$ in geitonogamy and $50.4 \%$ in open pollination experiments, whereas only $30.3 \%$ of fruit set was observed in xenogamy experiments (Table 2 ). The percentage of seed set per berry among the treatments varied significantly $(p \leq 0.05)$ with the minimum number $(23 \pm 2.3 \%)$ shown by xenogamy treatments. Seeds formed via pollination experiments were evaluated for germination. Autogamously formed seeds showed significantly higher germination percentage of $70.3 \%$ in passive autogamy and $68 \%$ in active autogamy than geitonogamy and open pollination ( $60 \%$ each), however seeds obtained from xenogamy treatment showed the minimum germination percentage of $40.3 \%$ (Table 2 ).

Table 2. Details of pollination treatments, percentage fruit set and their seed germination in $W$. ashwagandha. 


\begin{tabular}{|c|c|c|c|c|}
\hline \multicolumn{5}{|c|}{ S. No. Treatment applied Fruit set $(\%)$ No. of seeds per berry Seed germination (\%) } \\
\hline \multirow[t]{2}{*}{1.} & Passive autogamy & $90.8 \pm 1.68^{\mathrm{a}}$ & $35 \pm 1.2^{\mathrm{a}}$ & $70.3 \pm 4.41^{\mathrm{a}}$ \\
\hline & & $(n=200)$ & & \\
\hline \multirow[t]{2}{*}{2.} & Assisted autogamy & $65.0 \pm 2.15^{\mathrm{b}}$ & $35 \pm 2.3^{\mathrm{a}}$ & $68.0 \pm 4.45^{\mathrm{a}}$ \\
\hline & & $(n=200)$ & & \\
\hline \multirow[t]{2}{*}{3.} & Geitnogamy & $56.5 \pm 3.27^{\mathrm{c}}$ & $30 \pm 1.9^{b}$ & $60.0 \pm 2.23^{\mathrm{b}}$ \\
\hline & & $(n=250)$ & & \\
\hline \multirow[t]{2}{*}{4.} & Xenogamy & $30.3 \pm 2.71^{\mathrm{d}}$ & $23 \pm 2.3^{c}$ & $40.3 \pm 5.15^{\mathrm{c}}$ \\
\hline & & $(n=200)$ & & \\
\hline & Open pollination & $50.4 \pm 1.50^{\mathrm{e}}$ & $28 \pm 1.3^{\mathrm{b}}$ & $60.0 \pm 2.68^{b}$ \\
\hline & & $(n=300)$ & & \\
\hline
\end{tabular}

The differences in percentage fruit set, seed set and germination percentage among the treatments are significant $(p<0.05)$ by paired ' $t$ ' test. The " $n$ " represents the number of flowers used for the treatment.

\section{Discussion}

Under experimental condition of the institute, optimum flowering of the species under study was observed during April-July. Flowers were small (4-6 $\mu \mathrm{m})$, complete, lurid yellow, sub-sessile and bisexual and 3-6 flowers are arranged in axillary cluster or forming umbellate cymes. The pollen grains were trizonocolporate with scabrate-granulate exine sculpturing (Fig. 1) and of uniform size $(28.0 \mu \mathrm{m})$. The average number of ovules/flower was $38 \pm 1.20$. Pollen viability remained approximately the same up to $12 \mathrm{~h}$ of storage in $2 \%$ sucrose and gradually decreased thereafter. An interesting feature of this species is that anthers dehisced two days after anthesis exactly at the same time when the stigma is receptive (Table 1). Initially the stamens are short but as the anthesis proceeds, they elongate and anthers touch the stigma on the inner side ensuring sufficient pollen deposition on it. Thus, there seems to be a signal mechanism operating at the time of stigma receptivity. An important result of this synchrony and proximity of stigmatic surface with dehiscing anthers is to create ideal conditions for selfing. Similar mechanism of anther-stigma proximity ensuring selfing was also reported in Petrocoptis viscose (Guitian and Navarro, 2002). Self pollination predisposing the similar mechanism has also been reported in few other species e.g. Bixa orellana (Renata et al., 2006), W. somnifera ( Kaul et al., 2005, Mir, 2010 and Mir et al., 2012). Similarly high pollen load on the stigma and stiff pollen competition within a flower with about 611 pollen grains available for siring one ovule, greatly reduce the possibility of cross-pollination. Floral features like small size of flowers, dull green color, high fruit: flower and seed: ovule ratios, are also associated with autogamy. High p/o ratio favors for strong out crossing whereas low $\mathrm{p} / \mathrm{o}$ ration is in conformity with the prediction for autogamous species (Cruden, 1977). Thus based on the p/o ratio categories as proposed by Cruden (1977) W. ashwagandha would be an obligate autogamous species with low p/o ratio of 611:1. The low p/o ratio was also observed by Amorim et al. (2011) in Passiflora capsularis and P. rubra two obligatory autogamous species. The infrequent visits of insects on flowers and the insignificant pollen load carried by them further reduce the chances of cross-pollination.

Results of pollination experiments showed that whereas $90.8 \%$ fruit could develop through passive autogamy, only $65 \%$ fruit developed from assisted autogamy. In both these treatments stigma receive pollen from own flowers but in different manners. The manual transfer of pollen 
in active autogamy significantly decreased fruit set indicating that pollen grains do not depend on external agency to reach the stigma surface of the same flower. However, the success of assisted autogamy depends upon frequency of pollen transfer and stigma receptivity (Shivanna and Ram, 1993 and Chauhan et al., 2008). Higher fruit and seed set in controlled self pollination over other pollination treatments (Table 2) further confirms that the species is independent of pollinator visits for reproductive success. Nevertheless, the possibility of a degree of cross pollination cannot be ruled out due to prior exposition of stigma. The higher values of fruit and seed set in passive autogamy further indicate that self pollen grow, germinate and penetrate the pollen tubes into the ovules while in other treatments pollen tubes may not penetrate the ovules indicating flower and fruit abortions. Besides timing of pollen maturation and deposition play an important role with only very recently matured pollen working well. Unattractive flowers pre-dispose the species to an insignificant contribution of insect visitors in pollination. This is a common feature of other self pollinating plant species as well (Primack, 1985, Kaul et al., 2005 and Singh, 2009). Studies conducted by Shivanna and Ram (1993) and Chauhan et al. (2008) reported the requirement of pollinator in self-compatible flowers of Lantana camara and Nardostachys jatamansi respectively. Seeds developed via pollination experiments showed interesting results; seed germination was significantly higher in seeds obtained in autogamy than geitonogamy, open pollination and xenogamy treatments (Table 2).

The self compatible nature of the species was confirmed by a high percentage of fruit and seed set in controlled self pollination (Table 2). Low fruit set on cross pollination after emasculation was another pointer to the partial fixation of autogamy in the species. Flowering plants possess a wide array of morphological and physiological mechanisms that influence mating patterns, particularly the degree of self fertilization (Eckert and Barrett, 1994 and Gituru et al., 2002).

\section{Conclusion}

A high percentage of fruit and seed set in controlled self pollination experiments in $W$. ashwagandha confirmed its self-compatible nature. Results of pollination experiments also confirm absence of apomixis. The floral architecture especially relative size and close proximity of stigma and anthers predispose the species for self pollination. The species shows rare occurrence in natural habitats; it needs conservation via 'in situ' as well as 'ex situ' methods. Large scale cultivation in its natural habitat on one hand and limited exploitation for the market demand on the other is the only option for conservation. Breeding experiments of this medicinally important plant species (especially xenogamy) will open new dimensions for genetic improvement of crop in future. Further, the information generated by the present study will help in development of hyper-productive varieties with respect to withanolides content and root biomass by inter varietal crosses besides being useful for studying the chemogenetic inheritance of withanolides.

\section{Acknowledgements}

Authors are grateful to Director, Indian Institute of Integrative Medicine (IIIM), Jammu for providing the necessary facility. Thanks are due to Dr. M. K. Kaul for his constant encouragement and help. Thanks are also due to Dr. Rajesh Tandon, Department of Botany, University of Delhi for his useful suggestions in manuscript preparation. The author also 
acknowledge the University of Pretoria for providing Vice-Chancellors Post Doctoral Fellowship.

\section{References}

Amorim,J.D.S., Souza, M.M., Viana, AJ.C, Freitas,J.C.D., 2011. Self, cross- and interspecific pollinations in Passiflora capsularis and P. rubra. Revista Brasil. Bot. 34 (4), $537-544$.

Anderson, G.J., Bernardello, G., Opel, M.R., Guerra, A.S., Anderson, M., 2006. Reproductive biology of the dioecious canary island endemic Withania aristata (Solanaceae). Am.J. Bot. 93 (9), 1295-1305.

Anderson, G.J., Hill, G.D., 2002. Many to flower, few to fruit: the reproductive biology ofHemimalis ve ${ }^{\wedge} \mathrm{n} /$ ana (Hemimalidaceae). Am.J. Bot. 89 (1), 67-78.

Atal, C.K. Schwarting, A.E., 1962. Intraspecific variability in Withania somnifera I. A preliminary survey. Llyodia $25,78-88$.

Caccavari, M., Dome, E., 2000. An account of morphological and structural characterization of American mimosoideae pollen. Part I: Tribe Acacieae. Palynology 24, 231-248.

Chauhan, R.S., Kaul, M.K., Kumar, A., Nautiyal, M.C., 2008. Pollination behaviour of Nardostachys jatamansi DC. An endangered medicinal and aromatic herb. Sci. Hortic. 117, 78-81.

Cruden, R.W., 1977. Pollen-ovule ratio: a conservative indicator of breeding system in plants. Evolution 31,32-46.

Dafni, A., 1992. Pollination Ecology: A Practical Approach. Oxford University Press, New York.

Davis, L, Kuttan, G., 2002. Effect of Withania somnifera on CTL activity. J. Exp. Clin. Cancer Res. 21,115-118.

Dhalla, N.S., Gupta, K.C., Sastry, N.S., Malhotra, C.L., 1961. Comparative studies on Withania somnifera Dunnl and Withania ashwagandha Kaul. Ind. J. Pharmacol. 23,126-127.

Eckert, C.G., Barrett, S.C.H., 1994. Post-pollination mechanism and the maintenance of out crossing in selfcompatible, tristylous, Decodon verticillatus (Lythraceae). Hereditary 72,396-411.

Gituru, W.R., Wang, Q.F., Wang, Y., Guo, Y.H., 2002. Pollination ecology, breeding system and conservation of Caldesia grandis (Alismataceae) an endangered marsh plant in china. Bot. Bull. Acad. Sin. 43, $231-240$.

Guitian, J., Navarro, L, 2002. The role of floral biology and breeding system on the reproductive success of the narrow endemic Petrocoptis viscose Rolhm. (Caryophylaceae). Biol. Conserv. 103,125-132.

Kaileh. M., Berghe, W.V., Boone, E. Essawi, T., Haegeman, G., 2007. Screening of indigenous Palestinian medicinal plants for potential anti-inflammatory and cytotoxic activity. J. Ethnopharmacol. 113, $510-516$.

Kaul, K.N.,1957. The origin, distribution and cultivation of Ashwagandha the so called Withania somnifera of Indian literature. In: Symposium on the Utilization of Indian Medicinal Plants. CSIR, New Delhi, pp. 7-8.

Kaul, M.K., Kumar, A., Sharma, A., 2005. Reproductive biology of Withania somnifera (L) Dunal. Curr. Sci. 88 (9), 1375-1377.

Kaye, T.N., 1999. From flowering to dispersal: reproductive biology of an endemic plant, Austragalus australis Var. Plympicus (Fabaceae). Am. J. Bot. 86 (9), 1248-1256.

Koduru, S., Kumar, R., Srinivasan, S., Evers, M.B., Damodaran, C, 2010. Notch-1 inhibition by Withaferin-A: a therapeutic target against colon carcinogenesis. Mol. Cancer Ther.' 9, 202-210.

Koul, M.M., Bhatnagar, A.K., 2007. Plant reproductive biology studies crucial for conservation. Curr. Sci. 92 (9), 1207.

Kumar, A., Mir, B.A., Sehgal, D., Koul, S., Dar, T.H., Maharaj, K.K., Soom, N.R., Qazi, G.N., 2011. Utility of multidisciplinary approach for genome diagnostics of cultivated and wild germplasm resources of medicinal Withaniasomnifera, and status of new species, W. ashwagandha, in the cultivated taxon. Plant Syst. Evol. 291, 141-151.

Kuttan, G., 1996. Use of Withania somnifera Dunal as an adjuvant during radiation therapy. Indian J. Exp. Biol. 34, 854-856.

Lalonde, R.G., Roitberg, B.D., 1994. Mating system, life history and reproduction in Canada thistle (Circium arvense; Asteraceae). Am. J. Bot. 81, 21-28. 
Lattoo, S.K., Dhar, R.S., Khan, S., Bamotra, S., Dhar, A.K., 2007. Temporal sexual maturation and incremental staminal movement encourages mixed mating in Withania somnifera - an insurance for reproductive success. Curr. Sci. 92 (10), 1390-1399.

Lee, J., Hahm, E.R., Singh, S.V., 2010. Withaferin A inhibits activation of signal transducer and activator of transcription 3 in human breast cancer cells. Car-cinogenesis31 (11), 1991-1998.

Lewis, K.R., John, V.B., 1963. Chromosome Marker. Churchil, London.

Mahajan, B.K., 1989. Methods in Biostatistics.J. P. Brothers, New Delhi.

Mayola, E., et al., 2011. Withaferin A induces apoptosis in human melanoma cells through generation of reactive oxygen species and down-regulation of Bcl-2. Apoptosis, http://dx.doi.org/10.1007/s10495-011-0625-x.

Mir, B.A., 2010. Characterization of genetic variability in Withania somnifera using biochemical and molecular markers. Thesis Submitted to Guru Nanak Dev University. Amritsar, India.

Mir, B.A., Koul, S., Kumar, A., Kaul, M.K., Soodan, A.S., Raina, S.N., 2010. Intraspecific Variation in the Internal Transcribed Spacer (ITS) Regions of rDNA in Withania somnifera (L.) Dunal. Ind. J. Biotechnol. 9 (3), $325-328$.

Mir, B.A., Koul, S., Kumar, A., Sharma, S., Kaul, M.K., Soodan, A.S., 2012. Reproductive behaviour and breeding system of wild and cultivated types of Withania somnifera (L.) Dunal. J. Med. Plants Res. 6 (5), $754-762$.

Mir, B.A., Kumar, A., Koul, S., Kaul, M.K., Raina, S.N., Soodan, A.S., 2011. Assessment and Characterization of genetic diversity in Withania somnifera (L.) Dunal using RAPD and AFLP markers. Afr. J. Biotechnol. 10(66), 14746-14756.

Neal, P., Anderson, G.J., 2005. Are 'mating systems' 'breeding systems' of inconsistent and confusing terminology in plant reproductive biology? Or is it the other way around? Plant Syst. Evol. 250, 173-185.

Negi, M.S., Sabharwal, V., Wilson, N., LakshmiKumaran, M.S., 2006. Comparative analysis of the efficiency of SAMPL and AFLP in assessing genetic relationships among Withania somnifera genotypes. Curr. Sci. 91, 464471 .

Primack, R.B., 1985. Patterns of flowering phenology in communities, populations, individuals and single flowers. In: White, J. (Ed.), The Population Structure of Vegetation. DrJunck Publishers, Dordrecht, pp. 571-593.

Renata, R., Rosa, M., Eric, B., Maria, V.. Huges, H., 2006. Preliminary studies towards genetic improvement of annatto(B/xa orellana L). Sci. Hortic. 109(2), $165-172$.

Sastry, M.S., Dhalla, N.S., Malhotra, C.L., 1960. Chemical examination of Withania ashwagandha Kaul. Ind.J. Pharmacol. 22, 205 .

Shivanna, K.R., Ram, H.Y.M., 1993. Pollination biology: contribution to fundamental and applied aspects. Curr. Sci. 65 (3), 226-232.

Singh, V., 2009. Phenology and Reproductive Biology of Withania somnifera (L.) Dunal (Solanaceae). J. Plant Rep. Biol. i (1), 81-86.

Stanley, R.G., Linskens, H.F., 1974. Pollen Biology, Biochemistry and Management. Springer Verlag, New York.

Yang, E.S., Choi, M.J., Kim, J.H., Choi, K.S., Kwon, T.K., 2011. Withaferin A enhances radiation-induced apoptosis in Caki cells through induction of reactive oxygen species, Bcl-2downregulationand Akt inhibition. Chem. Biol. Int. 190(1), 9-15. 